Published in final edited form as:

Gastroenterology. 2017 March ; 152(4): 830-839.e5. doi:10.1053/j.gastro.2016.11.043.

\title{
Prevalence and Morbidity of Undiagnosed Celiac Disease From a Community-based Study
}

\author{
Rok Seon Choung, MD, PhD ${ }^{1}$, Scott A. Larson ${ }^{1}$, Shahryar Khaleghi, Pharm $\mathrm{D}^{1}$, Alberto \\ Rubio-Tapia, MD ${ }^{1}$, Inna G. Ovsyannikova, $\mathrm{PhD}^{2}$, Katherine S. King ${ }^{3}$, Joseph J. Larson ${ }^{3}$, \\ Brian D. Lahr ${ }^{3}$, Gregory A. Poland, MD², Michael J. Camilleri ${ }^{4}$, and Joseph A. Murray, MD ${ }^{1}$ \\ ${ }^{1}$ Division of Gastroenterology and Hepatology, Mayo Clinic, Rochester, Minnesota, USA \\ ${ }^{2}$ Mayo Clinic Vaccine Research Group, Mayo Clinic, Rochester, Minnesota, USA \\ ${ }^{3}$ Division of Biomedical Statistics and Informatics, Mayo Clinic, Rochester, Minnesota, USA \\ ${ }^{4}$ Departments of Dermatology and Laboratory Medicine and Pathology, Mayo Clinic, Rochester, \\ Minnesota, USA
}

\begin{abstract}
Background \& Aims-Little is known about the prevalence and burden of undiagnosed celiac disease in individuals younger than 50 years old. We determined the prevalence and morbidity of undiagnosed celiac disease in individuals younger than 50 years in a community.

Methods-We tested sera from 31,255 residents of Olmsted County, Minnesota (younger than 50 years old) without a prior diagnosis of celiac disease assay using an assay for immunoglobulin A (IgA) against tissue transglutaminase (tTG); in subjects with positive test results, celiac disease was confirmed using an assay for endomysial IgA. We performed a nested case-control study to compare the proportion of comorbidities between undiagnosed cases of celiac disease and ageand sex-matched seronegative controls (1:2). Medical records were abstracted to identify potential comorbidities.
\end{abstract}

Results-We identified 338 of 30,425 adults with positive results from both serologic tests. Based on this finding, we estimated the prevalence of celiac disease to be $1.1 \%$ (95\% CI, $1.0 \%-$

Correspondence: Address correspondence to Joseph A. Murray, MD, Mayo Clinic, 200 First Street SW, Rochester, MN 55905 USA. Phone: 507-255-5713. Fax: 507-255-6318. murray.joseph@mayo.edu.

Disclosures: Dr. Joseph Murray has received grant support from the National Institutes of Health and Alba Therapeutics; receives ongoing support from Oberkotter Foundation and Broad Medical Research Program at CCFA; serves on the advisory board of Celimmune, LLC; was a consultant to AMAG Pharmaceuticals, Entera Health, Inc, Sonomaceuticals, LLC, BioLineRx, GlaxoSmithKline (GSK), Genentech, and Glenmark Pharmaceuticals Ltd; serves as a consultant to Boehringer Ingelheim; has a patent with Miomics; and has equity options in Torax. The remaining authors have no conflicts to disclose.

Author Contributions: Study concept and design: RSC, SAL, JAM

Analysis and interpretation of data: RSC, SAL, SK, ART, JAM

Drafting of manuscript, critical revision of manuscript for important intellectual content: RSC, SAL, ART, BDL, JAM

Statistical analysis: JJL, BDL, KSK

Material and support: IGO, GAP, MJC

Study supervision: JAM

Publisher's Disclaimer: This is a PDF file of an unedited manuscript that has been accepted for publication. As a service to our customers we are providing this early version of the manuscript. The manuscript will undergo copyediting, typesetting, and review of the resulting proof before it is published in its final citable form. Please note that during the production process errors may be discovered which could affect the content, and all legal disclaimers that apply to the journal pertain. 
$1.2 \%) ; 8$ of 830 children tested positive for IgA against tTG (1.0\%, 95\% CI, $0.4 \%-1.9 \%)$. No typical symptoms or classic consequences of diagnosed celiac disease (diarrhea, anemia, or fracture) were associated with undiagnosed celiac disease. Undiagnosed celiac disease was associated with increased rates of hypothyroidism (odds ratio, 2.2; $\mathrm{P}<.01$ ) and lower than average level of cholesterol $(\mathrm{P}=.03)$ and ferritin $(\mathrm{P}=.01)$. During a median follow-up period of 6.3 years, the cumulative incidence of subsequent diagnosis with celiac disease at 5 years after testing was $10.8 \%$ in persons with undiagnosed celiac disease vs $0.1 \%$ in seronegative persons $(\mathrm{P}<.01)$. Celiac disease status was not associated with overall survival.

Conclusions-Based on serologic tests of a community population for celiac disease, we estimated the prevalence of undiagnosed celiac disease to be $1 \%$. Undiagnosed celiac disease appeared to be clinically silent and remained undetected, but long-term outcomes have not been determined.

\section{Keywords}

mortality; epidemiology; small intestine; autoimmune disease

\section{INTRODUCTION}

Celiac disease is an immune-mediated multisystem disorder triggered by the ingestion of gluten, possibly affecting approximately $1 \%$ of the US white population. ${ }^{1,2}$ Symptomatic celiac disease is associated with substantial morbidity and a modest increased mortality risk. ${ }^{3-10}$ A study from Sweden demonstrated increased mortality risk in patients with villous atrophy, inflammation (Marsh I/II), and latent celiac disease (defined by positive serology with normal histologic findings) in both children and adults. ${ }^{11}$ However, a recent large database study of England did not show an increased mortality rate for patients with diagnosed celiac disease. ${ }^{12}$ Strict adherence to a gluten-free diet (GFD) improves gastrointestinal symptoms within weeks and may decrease the risks of both severe complications and death, especially when mucosal recovery has been achieved. ${ }^{13-16}$

Despite the availability of effective therapy, most individuals with celiac disease remain undetected and subject to the development of consequences of hidden disease. ${ }^{17,} 18$ Previously, we demonstrated that individuals with undiagnosed celiac disease had increased risk of comorbid conditions in people aged 50 years or older. ${ }^{19}$ In addition, based on a military based cohort, we demonstrated that undiagnosed celiac disease in adults has been shown a nearly 4 -fold increased risk of death over 45 years of follow-up ${ }^{2}$; however other studies have not shown an increased risk of death ${ }^{12,20}$, and information regarding morbidity in adults with undiagnosed celiac disease is scarce. Further, the natural history of undiagnosed celiac disease is incompletely understood: ${ }^{21-24}$ whether any of them will stay clinically silent or progress to clinically obvious celiac disease. The aims of this study were to determine the prevalence, determine the identifying features, and evaluate morbidity of undiagnosed celiac disease in adults aged 18 to 50 years in a community. We also evaluated celiac disease outcomes, including subsequent diagnosis and survival in a community-based cohort of adults identified with undiagnosed celiac disease. 


\section{MATERIALS AND METHODS}

This study is a community- based nested case-control study of individuals aged less than 50 years old, whose waste blood samples were tested for antibodies associated with celiac disease in 2006 through 2011. Our study was approved by the institutional review boards of Mayo Clinic and Olmsted Medical Center, Rochester, Minnesota.

\section{Setting}

Subjects are residents of Olmsted County, Minnesota, which has about 120,000 residents. The population has been repeatedly studied because its medical care is virtually selfcontained within the community; it is one of a few US communities where population-based studies can be conducted. ${ }^{25-28}$ The 2010 US census data showed that about $89 \%$ of residents in this community are White, and the county has been determined to be representative of the United States. ${ }^{28,}{ }^{29}$ Mayo Clinic and Olmsted Medical Center are the major providers of medical care to residents in the county, and over any 4-year span, almost all residents see a provider at one of these health centers. ${ }^{25,}$ 26, 28, 29 The Rochester Epidemiology Project is a study funded by the National Institutes of Health that links all providers in Olmsted County and provides a unique records linkage system so that accurate medical information and representative samples can be obtained.

\section{Subjects}

Approximately 65,000 adults (age, 18-50 years) lived in Olmsted County per year from 2006 through 2011, based on the 2010 US census data. Over this time, we collected serum samples of patients in this age-group who were seen at Mayo Clinic. We identified patients who had residual blood samples available for general research. Patients with known celiac disease diagnosed before or 2 weeks after serum draw or patients without research authorization were excluded from the study. Samples were retrieved from 30,425 adults whose samples were screened for celiac disease serologic findings. In addition, we tested samples of 250 children who had residual blood samples available for general research and samples of 580 children who were from age-stratified random cohorts of healthy children in Rochester, MN. ${ }^{30,31}$ The Pediatric samples were only tested for tissue transglutaminase antibody-immunoglobulin A (tTGA) due to restriction of sample availability.

\section{Case Definition}

Samples were screened for celiac disease with sequential testing, with initial screening through tTGA enzyme-linked immunosorbent assay (Inova Diagnostics), as previously described. ${ }^{19}$ Positive test results were confirmed with endomysial antibody (EMA) immunofluorescence assay (Inova Diagnostics). Undiagnosed celiac disease was defined as tTGA $\geq 2.0 \mathrm{U} / \mathrm{mL}$ and a positive EMA test. A tTGA level $<2.0 \mathrm{U} / \mathrm{mL}$ was considered negative, and therefore no EMA test was done. In addition, samples were considered negative when tTGA was 2.0 to $4.0 \mathrm{U} / \mathrm{mL}$ and EMA test was negative. Samples were considered equivocal when tTGA exceeded $4.0 \mathrm{U} / \mathrm{mL}$ and EMA test was negative. As previously reported, a positive fluorescence at dilutions equal to or greater than 1:5 was considered positive for EMA immunofluorescence assay. ${ }^{32}$ This sequential testing paradigm, using subsequent EMA testing for positive tTGA result, showed a sensitivity of $97 \%$ and a 
specificity of $100 \%$ for celiac disease in a prior investigation done with parallel study of this exact serologic strategy and histologic evaluation. ${ }^{33,34}$

Each case was matched by age, gender, the time of serum collection, and Mayo Clinic registration year, two controls with negative celiac disease serology that were selected from the same population. All samples were removed of patient identifiers and testing was performed with no knowledge of the patients' clinical data. Ultimately 281 individuals could be used in the nested study of undiagnosed celiac disease based on serology testing and authorization of medical records for research.

\section{Data Collection}

Serum status was masked to the persons who reviewed the medical records for information before the serum draw date. The records contained inpatient, outpatient, and emergency department data. To obtain information of known comorbid conditions related to celiac disease, the diagnosis lists, outpatient notes, hospital notes, and laboratory results were evaluated, as well as follow-up data on mortality. In laboratory testing review, the values used were those obtained nearest the serum draw date.

For identifying the subsequent diagnosis of celiac disease, several data sources including celiac disease registry database were utilized, which were used in our previous study estimating the incidence of celiac disease in residents of Olmsted County. Briefly, the diagnosis codes for celiac disease through the Rochester Epidemiology Project that were used in our previous studies were sensitive to find potential celiac disease patients, and then the diagnoses of these patients were confirmed by the electronic medical record that contains information on serology and histopathology data.

\section{Statistical Analysis}

Descriptive statistics used to summarize baseline data included number (percentage) for categorical data and mean (standard deviation [SD]) or median (interquartile range [IQR]) for continuous data. Discrete numeric variables that represent counts were reported as mean (IQR) which is a more sensitive statistic than the median when there are excessive ties in the data (e.g., counts of 0).The extent of undiagnosed celiac disease among adults $\leq 50$ years old in the community was estimated as the observed proportion with positive serology, along with a 95\% "exact" confidence interval (CI, using the Clopper-Pearson method) to reflect this estimate's variability. Analyzed for the entire cohort, the Kaplan-Meier product limit method was used to estimate survival (from all-cause mortality) and cumulative event rate of subsequent celiac disease diagnosis, with group comparison of these rates evaluated with log-rank test. Median follow-up was estimated using the reverse Kaplan-Meier method, in which the standard calculation is modified by reversing the event indicator as if censoring were the outcome of interest.

On the matched subset of individuals with and without positive serology, we collected information on candidate risk factors, including comorbidities that occurred before the serum draw and laboratory measures collected within 1 year before or after serum draw. Each candidate risk factor was analyzed separately for an association with seropositive case status through conditional logistic regression or through regular logistic regression when 
extensive amounts of data (eg, laboratory parameters) were missing. In all models, the matching variables age and sex were included as adjusting covariates to control for any residual confounding not prevented by the matching itself. Odds ratios (ORs) (95\% CIs) are reported to measure the strength of association of the candidate predictor with serology status. For laboratory and hospital utilization measures with skewed distributions, data was analyzed in conditional logistic regression based on log-transformed values (ORs were expressed per 1 SD increase on log-scale). We also performed a sensitivity analysis retesting these associations on an augmented matched subset in which tTGA result, not serology result, was the basis of the matching. For this we retained all original matched sets in which the seropositive case had positive tTGA $(\geq 4.0 \mathrm{U} / \mathrm{mL})$ and both controls had negative tTGA $(<4.0 \mathrm{U} / \mathrm{mL})$, and additionally included those with equivocal serology who had positive tTGA along with corresponding matched controls.

All analyses were uncorrected for multiple testing and adhered to a liberal significance level of .05. Given that numerous factors were analyzed for an association (in all, nearly 80 comorbid conditions, diseases, and laboratory variables), these findings should be considered hypothesis-generating and interpreted cautiously. All analyses were performed using statistical software (version 9.3; SAS Institute Inc).

\section{RESULTS}

\section{Prevalence of Undiagnosed celiac disease}

From residents (age, 18-50 years) of Olmsted County who sought health care at Mayo Clinic from 2006 through 2011, we obtained and tested waste serum samples of 30,425 individuals. In total, 372 persons (1.2\%) tested positive for tTGA ( $\geq 4.0 \mathrm{U} / \mathrm{mL}), 241(0.8 \%)$ had borderline tTGA levels $(2.0 \unlhd \mathrm{TG}<4.0 \mathrm{U} / \mathrm{mL})$, and 29,812 (98.0\%) tested negative. Those with a positive or borderline tTGA result underwent confirmatory EMA testing. On the basis of a combined serology status of tTGA and EMA results, 57 persons were considered of equivocal status (tTGA $\geq 4.0 \mathrm{U} / \mathrm{mL}$, with negative EMA test) and were removed from the denominator for estimating the rate with positive serology. Based on the 338 persons with a combined seropositive result for celiac disease from the final denominator of 30,368 persons, the estimated prevalence of undiagnosed celiac disease in the Olmsted County residents age $18-50$ was $1.1 \%$ (95\% CI, $1.0 \%-1.2 \%$ ). The estimate appeared to be slightly higher in women $(1.2 \% ; 95 \% \mathrm{CI}, 1.0 \%-1.4 \%)$ than men $(1.0 \%, 95 \%$ $\mathrm{CI}=0.8 \%-1.2 \%)$, but this difference was not statistically significant $(P=.07)$. In addition to adults, we collected and tested sera of 830 children aged less than 18 years who resided at Olmsted County, in whom 8 children were found to have positive tTGA. Figure 1 showed the overall prevalence of undiagnosed celiac disease based on tTG positivity by age categories.

\section{Subsequent Clinical Detection}

During a median follow-up of 6.3 years, 74 individuals from the cohort had received a subsequent clinical diagnosis of celiac disease at time of analysis, which corresponded to a 5 -year cumulative event rate of $0.2 \%$ (95\% CI, $0.2 \%-0.3 \%$ ). Women accounted for 52 of these celiac disease diagnoses and showed slightly higher rates compared to men (5-year 
event rate, $0.3 \%$ vs. $0.2 \%$, respectively), although formal comparison showed only a borderline difference that was not statistically significant $(P=.05)$.

Figure 2 shows the cumulative incidence of clinical diagnosis among persons in the cohort, grouped in the first panel according to serology result (after those with equivocal serology were excluded) and in the second panel according to tTGA result (all cohort members were included). Compared to rates in seronegative persons (5-year event rate, $0.1 \%$; 95\% CI, $0.1 \%-0.2 \%$ ), the frequency of clinical diagnosis after blood draw was significantly higher in persons with undiagnosed celiac disease (5-year event rate, 10.8\%; 95\% CI, 7.2\%-14.4\%; $P<.01)$. Of the 38 seropositive patients who received a celiac disease diagnosis, abdominal cramping (53\%) and abdominal distention (39\%) were the most common presenting symptoms. Interestingly, only $8 \%$ of these patients had presented with classic symptoms of diarrhea and weight loss at the time of celiac disease diagnosis.

Figure 3 shows the cumulative event rate of clinical diagnosis estimated as a function of age rather than time after blood draw. Among individuals with positive serology who had available follow-up beyond age 25, the rate of diagnosis appeared to be fairly linear across age, with approximately half of sero-positives diagnosed with celiac disease by age 53 . Likewise, approximately $50 \%$ of individuals with tTGA $\geq 10 \mathrm{U} / \mathrm{mL}$ received a celiac disease diagnosis by age 50 , compared to $30 \%$ of those with tTGA $4-10 \mathrm{U} / \mathrm{mL}$ and $<1 \%$ of those with tTGA $<4 \mathrm{U} / \mathrm{mL}$.

\section{Survival}

In this adult cohort, rates of all-cause mortality were generally low across study follow-up (overall 5-year survival rate, 99\%). Of the 301 persons who died within 5 years of serum draw, 298 had a negative serologic result at baseline and 2 had positive serology. Survival was not significantly worse in persons with undiagnosed celiac disease than those with negative serology $(P=.18)$ (Figure 4).

\section{Comorbid Conditions}

Table 1 shows the demographic characteristics on the matched sample of cases with positive celiac disease serology and age- and sex-matched controls with negative serology. In general, patient characteristics were similar between the 2 groups, with the exception of race, which showed non-Caucasians were at lower risk of undiagnosed celiac disease than Caucasians ( $P=.02$ ). Interestingly, celiac disease serology status (undiagnosed celiac disease vs controls) was not found to be associated with typical celiac disease symptoms including diarrhea, weight loss, abdominal pain, anemia, and IBS (supplemental table 1). In particular, no difference was found in the proportion reported as having irritable bowel syndrome (3\% vs $4 \%$ ), weight loss (3\% vs $2 \%$ ), diarrhea ( $3 \%$ vs $3 \%$ ), and anemia (9\% vs $10 \%)$. Table 2 summarizes the distribution of comorbid conditions and laboratory findings in persons with undiagnosed celiac disease and their matched controls. Odds of having undiagnosed celiac disease were found to be increased in persons with hypothyroidism (OR [95\% CI], $2.2[1.2-$ 4.0]; $P<.01$ ) and those with a history of autoimmune disease (OR [95\% CI], 1.6 [1.1-2.3]; $P=.02$ ). However, no significant differences were identified for hyperthyroidism (1\% in persons with undiagnosed celiac disease vs $<1 \%$ in matched controls), type 1 diabetes 
mellitus ( $2 \%$ vs $1 \%$ ), glucose intolerance ( $3 \%$ vs $3 \%$ ), or neuropathy ( $2 \%$ vs $1 \%$ ). On the basis of unmatched comparisons on laboratory findings (Table 2), undiagnosed celiac disease was associated with reduced levels of ferritin (median, $13 \mathrm{ug} / \mathrm{L}$ vs $32 \mathrm{ug} / \mathrm{L}$; n=98) and cholesterol (mean, $180 \mathrm{mg} / \mathrm{dL}$ vs $188 \mathrm{mg} / \mathrm{dL}$; $\mathrm{n}=526$ ) in the respective subgroups with available measurements. None of these differences remained significant after adjustment for multiple comparisons.

Sensitivity analysis was performed on an augmented matched subset that was identified and compared on the basis of tTGA result, thereby allowing the inclusion of tTGA positive ( $\geq 4.0$ $\mathrm{U} / \mathrm{mL}$ ) individuals with negative EMA (i.e., equivocal serology) in addition to the original serology-based matched sets (Supplemental Table 2). These matched comparisons on 319 individuals with positive tTGA (regardless of EMA result) and 638 matched tTGA-negative controls demonstrated similar findings, although chronic fatigue was found to be significantly associated with positive tTGA (OR $[95 \% \mathrm{CI}], 1.9[1.2-3.0] ; P<.01)$. Since the current study is complementary to that previously performed among older adults (aged $\geq 50$ years old) in the same community, the comparison with the previous study ${ }^{19}$ is shown in supplemental table 3 .

\section{Health Care Utilization}

Health care utilization, as measured by numbers of inpatient, outpatient, and emergency visits, was additionally compared between groups during the period of five years prior and one year after serum collection. Table 3 summarizes the hospitalization visits according to celiac disease serology status. Undiagnosed celiac disease was associated with fewer ER visits in the six years around the time of serum collection, while frequencies of inpatient and outpatient visits were comparable between matched groups.

\section{DISCUSSION}

In this large, community-based cohort of health care-attending adults aged 18 to 50 years, the prevalence of undiagnosed celiac disease was $1.1 \%$ (95\% CI, 1.0\%-1.2\%), which is similar to other epidemiologic data in the United States. ${ }^{19,35}$ To our knowledge, this study is the largest and most comprehensively analyzed on comorbid conditions in adults aged 18 to 50 years with undiagnosed celiac disease. We found that undiagnosed celiac disease was associated with subtle differences in nutrition, including decreased levels of cholesterol and ferritin, but was not associated with typical symptoms of celiac disease. Further, the most comorbid conditions commonly related to clinically diagnosed celiac disease were not related to undiagnosed celiac disease, except hypothyroidism and a history of autoimmune disorders, compared with seronegative matched controls. Interestingly, we found about $11 \%$ of undiagnosed celiac disease persons were subsequently diagnosed (clinically) within 5 years of their positive test result.

Although the majority of patients with celiac disease (more than $80 \%$ ) have not received the diagnosis, serologic screening for celiac disease is still debated, mainly because evidence is lacking on the clinically deleterious outcome and benefits after a GFD has been followed. ${ }^{36-38}$ Moreover, recent birth cohort studies have shown that in the patients with celiac disease susceptibility genes, celiac disease autoimmunity develops in early life, 
especially at an age $<5$ years. 39,40 Thus, patients with undiagnosed celiac disease conceivably may have atypical or mild symptoms, but their celiac disease continues to be unrecognized over a long duration and perhaps even for life.

In contrast to most of other studies in children, ${ }^{39-41}$ which reported a female preponderance in celiac disease, our study showed that the seroprevalence of celiac disease in adults was not significantly different between men and women. Another study based on a representative sample of the US population, which included children and adults, we also showed that seroprevalence of undiagnosed celiac disease was similar in men and women. ${ }^{42}$ This discrepancy data could be from the different study population such as high risk population vs. general population. In addition, biological difference could be much more influential in the early occurrence of disease. Further studies are warranted to explore the gender differences in celiac disease.

Our study showed from analyses uncorrected for multiple comparisons that hypothyroidism was associated with undiagnosed celiac disease. Moreover, we found some laboratory measures, including cholesterol and ferritin, were lower in undiagnosed celiac disease than in matched controls. These findings are partly consistent with results of a previous study ${ }^{19}$ showing that undiagnosed celiac disease is associated with increased risk of comorbid conditions in older adults, as well as findings of other studies of patients with clinically detected celiac disease. ${ }^{43,44}$ Furthermore, we found the difference of laboratory parameters between those with and without positive serology. In particular, we found lower ferritin levels in undiagnosed celiac disease than controls, and although proportions with anemia did not differ between groups, the association between deficient ferritin and undiagnosed celiac disease shows some parallels to the association between anemia and diagnosed celiac disease. ${ }^{45}$ Excess comorbid conditions and reduced nutritional markers such as lower cholesterol may result from a long duration of disease progression. ${ }^{19,} 46$ Recently, Kurppa et $\mathrm{al}^{16}$ reported that screen found asymptomatic adults with celiac disease benefited from a GFD, compared with untreated screen found celiac disease patients. Although current practice for the detection of celiac disease largely relies on the development of sufficient symptoms allied with clinical suspicion to enable the diagnosis of celiac disease, we found only $11 \%$ of undiagnosed celiac disease was subsequently diagnosed over a median of 6.3 years follow-up. This result is suggestive that the most persons with undiagnosed celiac disease do not have clinical symptoms or problems that sufficiently incite clinical attention to celiac disease in Olmsted County, a community with excellent access to medical care and a sustained increased rate of celiac disease diagnosis. ${ }^{47}$ In a study of pediatric patients, van Koppen et $\mathrm{al}^{22}$ conducted a prospective 10-year follow-up of 32 children who had celiac disease identified through mass screening. Interestingly, they found that $59 \%$ of the children with undiagnosed celiac disease, who had positive serology for celiac disease and villous atrophy, did not have symptoms at screening. Among 8 of the asymptomatic children who continued to consume a gluten-containing diet, 6 children stayed symptom-free over the 10year follow-up, including 5 with persistently high levels of EMA and tTGA in serum. Moreover, following a GFD is not easy for many people and may have a negative effect on a person's life, related to psychological, sociological, and economic burden. ${ }^{48,}{ }^{49}$ Whitaker et $\mathrm{al}^{49}$ conducted a study about patient perceptions on the burden of GFD and showed that $27 \%$ of study participants, with a diagnosis of celiac disease but without classic celiac disease 
symptoms, regretted being diagnosed with their condition. Our study also showed that the presence of comorbid conditions in undiagnosed celiac disease was similar to the presence in controls. Therefore, further large longitudinal studies are warranted to identify which persons with undetected celiac disease are at high risk for the further development of symptomatic celiac disease.

Several population-based studies have shown an association of increased mortality risk in patients with celiac disease, $3,5,10,11$ but other studies have not. ${ }^{12,19,20}$ Moreover, studies of mortality in undetected celiac disease report contradictory findings, suggestive that it is either 4-fold that of the general population or not increased at all. 2, 19, 20, 50 Our study did not find an increased mortality rate in undiagnosed celiac disease compared with seronegative controls. However, based on a small number of mortality cases and relatively short-term follow-up, our results are not conclusive and much longer follow up is needed.

A potential limitation of this study is that we did not confirm the presence of celiac disease by small intestinal biopsy in our patients with celiac disease and controls. However, the sequential serologic approach vs duodenal biopsy showed high sensitivity and high specificity for celiac disease diagnosis in previous studies. ${ }^{34,51}$ Thus, misclassification bias should have been minimal. The symptoms and morbid conditions were not captured uniformly like by a survey or interview, rather these data were abstracted through medical chart review. Thus, systematic error including recall bias could be minimized since the most of medical conditions can be accurately identified through the review of medical chart. Even though we did not test IgA deficiency in the controls, the possibility of having celiac disease cases in this group is low because about 1 in 400 persons of the general population have $\operatorname{IgA}$ deficiency. Our data was derived from a study cohort that is predominately white $(92 \%$ within the matched subset), mirroring the ethnic composition of the Olmsted County population, which limits applicability of our findings to more diverse populations. ${ }^{29}$. Given that the prevalence of celiac disease has been shown to be more common in whites than in other ethnicities, we would expect our study estimate to more closely reflect the prevalence of undiagnosed celiac disease in a white US population. ${ }^{18}$ Furthermore, we tested only the waste samples collected from individuals who sought health care. Since this sample represents a potentially less healthy selection of adults in Olmsted County, our data may not be representative of the general population. Due to the relatively young age and short followup in our study population, it is difficult to assess the relative hazard of mortality in individuals with undiagnosed celiac disease, and a substantially longer period under observation is needed.

In conclusion, the estimated prevalence of undiagnosed celiac disease was 1.1\% among adults aged 18-50 years old from this North American community. The group with undiagnosed celiac disease had few clues to the diagnosis and little excess morbidity rate, except hypothyroidism, compared with age- and sex-matched seronegative controls in a community sample of Olmsted County residents age 18 to 50. Undiagnosed celiac disease is common in younger adults and children, although it appears to be clinically silent, and so far no excess mortality has been demonstrated. 


\title{
Supplementary Material
}

Refer to Web version on PubMed Central for supplementary material.

\section{Acknowledgments}

This study was made possible using the resources of the Rochester Epidemiology Project, which is supported by the National Institute on Aging of the National Institutes of Health under Award Number R01AG034676. The content is solely the responsibility of the authors and does not necessarily represent the official views of the National Institutes of Health. The authors acknowledge the expert assistance of Tricia L. Branter for the serological testing.

Funding: Funding for this study was provided in part by a grant from the National Institutes of Health (R01DK057892), by a grant from the National Institute of Arthritis and Musculoskeletal and Skin Diseases (Rochester Epidemiology Project Award Number R01AR30582), and by the Mayo Foundation for Medical Education and Research.

\author{
Abbreviations \\ EMA endomysial antibody \\ GFD gluten-free diet \\ IgA immunoglobulin A \\ OR odds ratio \\ tTGA tissue transglutaminase antibody
}

\section{References}

1. Green PH, Cellier C. Celiac disease. N Engl J Med. 2007; 357:1731-43. [PubMed: 17960014]

2. Rubio-Tapia A, Kyle RA, Kaplan EL, et al. Increased prevalence and mortality in undiagnosed celiac disease. Gastroenterology. 2009; 137:88-93. [PubMed: 19362553]

3. West J, Logan RF, Smith CJ, et al. Malignancy and mortality in people with coeliac disease: population based cohort study. Bmj. 2004; 329:716-9. [PubMed: 15269095]

4. Logan RF, Rifkind EA, Turner ID, et al. Mortality in celiac disease. Gastroenterology. 1989; 97:265-71. [PubMed: 2744350]

5. Peters U, Askling J, Gridley G, et al. Causes of death in patients with celiac disease in a populationbased Swedish cohort. Arch Intern Med. 2003; 163:1566-72. [PubMed: 12860579]

6. Corrao G, Corazza GR, Bagnardi V, et al. Mortality in patients with coeliac disease and their relatives: a cohort study. Lancet. 2001; 358:356-61. [PubMed: 11502314]

7. Solaymani-Dodaran M, West J, Logan RF. Long-term mortality in people with celiac disease diagnosed in childhood compared with adulthood: a population-based cohort study. Am J Gastroenterol. 2007; 102:864-70. [PubMed: 17324126]

8. Nielsen $\mathrm{OH}$, Jacobsen O, Pedersen ER, et al. Non-tropical sprue. Malignant diseases and mortality rate. Scand J Gastroenterol. 1985; 20:13-8. [PubMed: 3992161]

9. Cottone M, Termini A, Oliva L, et al. Mortality and causes of death in celiac disease in a Mediterranean area. Dig Dis Sci. 1999; 44:2538-41. [PubMed: 10630509]

10. Tio M, Cox MR, Eslick GD. Meta-analysis: coeliac disease and the risk of all-cause mortality, any malignancy and lymphoid malignancy. Aliment Pharmacol Ther. 2012; 35:540-51. [PubMed: 22239821]

11. Ludvigsson JF, Montgomery SM, Ekbom A, et al. Small-intestinal histopathology and mortality risk in celiac disease. JAMA. 2009; 302:1171-8. [PubMed: 19755695] 
12. Abdul Sultan A, Crooks CJ, Card T, et al. Causes of death in people with coeliac disease in England compared with the general population: a competing risk analysis. Gut. 2015; 64:1220-6. [PubMed: 25344479]

13. Rubio-Tapia A, Rahim MW, See JA, et al. Mucosal recovery and mortality in adults with celiac disease after treatment with a gluten-free diet. Am J Gastroenterol. 2010; 105:1412-20. [PubMed: 20145607]

14. Tursi A, Brandimarte G, Giorgetti GM, et al. Endoscopic and histological findings in the duodenum of adults with celiac disease before and after changing to a gluten-free diet: a 2-year prospective study. Endoscopy. 2006; 38:702-7. [PubMed: 16810593]

15. Galli G, Esposito G, Lahner E, et al. Histological recovery and gluten-free diet adherence: a prospective 1-year follow-up study of adult patients with coeliac disease. Aliment Pharmacol Ther. 2014; 40:639-47. [PubMed: 25066096]

16. Kurppa K, Paavola A, Collin P, et al. Benefits of a gluten-free diet for asymptomatic patients with serologic markers of celiac disease. Gastroenterology. 2014; 147:610-617. e1. [PubMed: 24837306]

17. Fasano A, Berti I, Gerarduzzi T, et al. Prevalence of celiac disease in at-risk and not-at-risk groups in the United States: a large multicenter study. Arch Intern Med. 2003; 163:286-92. [PubMed: 12578508]

18. Rubio-Tapia A, Ludvigsson JF, Brantner TL, et al. The prevalence of celiac disease in the United States. Am J Gastroenterol. 2012; 107:1538-44. quiz 1537, 1545. [PubMed: 22850429]

19. Godfrey JD, Brantner TL, Brinjikji W, et al. Morbidity and mortality among older individuals with undiagnosed celiac disease. Gastroenterology. 2010; 139:763-9. [PubMed: 20685275]

20. Canavan C, Logan RF, Khaw KT, et al. No difference in mortality in undetected coeliac disease compared with the general population: a UK cohort study. Aliment Pharmacol Ther. 2011; 34:1012-9. [PubMed: 21848796]

21. Ludvigsson JF, Card TR, Kaukinen K, et al. Screening for celiac disease in the general population and in high-risk groups. United European Gastroenterol J. 2015; 3:106-20.

22. van Koppen EJ, Schweizer JJ, Csizmadia CG, et al. Long-term health and quality-of-life consequences of mass screening for childhood celiac disease: a 10-year follow-up study. Pediatrics. 2009; 123:e582-8. [PubMed: 19336349]

23. Auricchio R, Tosco A, Piccolo E, et al. Potential celiac children: 9-year follow-up on a glutencontaining diet. Am J Gastroenterol. 2014; 109:913-21. [PubMed: 24777149]

24. Biagi F, Trotta L, Alfano C, et al. Prevalence and natural history of potential celiac disease in adult patients. Scand J Gastroenterol. 2013; 48:537-42. [PubMed: 23506211]

25. Melton LJ 3rd. History of the Rochester Epidemiology Project. Mayo Clin Proc. 1996; 71:266-74. [PubMed: 8594285]

26. Rocca WA, Yawn BP, St Sauver JL, et al. History of the Rochester Epidemiology Project: half a century of medical records linkage in a US population. Mayo Clin Proc. 2012; 87:1202-13. [PubMed: 23199802]

27. St Sauver JL, Grossardt BR, Yawn BP, et al. Data resource profile: the Rochester Epidemiology Project (REP) medical records-linkage system. Int J Epidemiol. 2012; 41:1614-24. [PubMed: 23159830]

28. St Sauver JL, Grossardt BR, Yawn BP, et al. Use of a medical records linkage system to enumerate a dynamic population over time: the Rochester epidemiology project. Am J Epidemiol. 2011; 173:1059-68. [PubMed: 21430193]

29. St Sauver JL, Grossardt BR, Leibson CL, et al. Generalizability of epidemiological findings and public health decisions: an illustration from the Rochester Epidemiology Project. Mayo Clin Proc. 2012; 87:151-60. [PubMed: 22305027]

30. Ovsyannikova IG, Dhiman N, Haralambieva IH, et al. Rubella vaccine-induced cellular immunity: evidence of associations with polymorphisms in the Toll-like, vitamin A and D receptors, and innate immune response genes. Hum Genet. 2010; 127:207-21. [PubMed: 19902255]

31. Ovsyannikova IG, Ryan JE, Vierkant RA, et al. Influence of host genetic variation on rubellaspecific T cell cytokine responses following rubella vaccination. Vaccine. 2009; 27:3359-66. [PubMed: 19200845] 
32. Chorzelski TP, Beutner EH, Sulej J, et al. IgA anti-endomysium antibody. A new immunological marker of dermatitis herpetiformis and coeliac disease. Br J Dermatol. 1984; 111:395-402. [PubMed: 6435666]

33. Aro P, Ronkainen J, Storskrubb T, et al. Valid symptom reporting at upper endoscopy in a random sample of the Swedish adult general population: the Kalixanda study. Scand J Gastroenterol. 2004; 39:1280-8. [PubMed: 15743007]

34. Walker MM, Murray JA, Ronkainen J, et al. Detection of celiac disease and lymphocytic enteropathy by parallel serology and histopathology in a population-based study. Gastroenterology. 2010; 139:112-9. [PubMed: 20398668]

35. Choung RS, Ditah IC, Nadeau AM, et al. Trends and racial/ethnic disparities in gluten-sensitive problems in the United States: findings from the National Health and Nutrition Examination Surveys from 1988 to 2012. Am J Gastroenterol. 2015; 110:455-61. [PubMed: 25665935]

36. Hoffenberg EJ, Liu E. Screening-identified celiac disease: who needs treatment and when? Clin Gastroenterol Hepatol. 2011; 9:284-5. [PubMed: 21238607]

37. Sandstrom O, Rosen A, Lagerqvist C, et al. Transglutaminase IgA antibodies in a celiac disease mass screening and the role of HLA-DQ genotyping and endomysial antibodies in sequential testing. J Pediatr Gastroenterol Nutr. 2013; 57:472-6. [PubMed: 23783015]

38. Hill ID. Screening for celiac disease. J Pediatr Gastroenterol Nutr. 2013; 57:414-5.

39. Lionetti E, Castellaneta S, Francavilla R, et al. Introduction of gluten, HLA status, and the risk of celiac disease in children. N Engl J Med. 2014; 371:1295-303. [PubMed: 25271602]

40. Vriezinga SL, Auricchio R, Bravi E, et al. Randomized feeding intervention in infants at high risk for celiac disease. N Engl J Med. 2014; 371:1304-15. [PubMed: 25271603]

41. Liu E, Lee HS, Aronsson CA, et al. Risk of pediatric celiac disease according to HLA haplotype and country. N Engl J Med. 2014; 371:42-9. [PubMed: 24988556]

42. Choung RS, Ditah IC, Nadeau AM, et al. Trends and racial/ethnic disparities in gluten-sensitive problems in the United States: findings from the National Health and Nutrition Examination Surveys from 1988 to 2012. Am J Gastroenterol. 2015; 110:455-61. [PubMed: 25665935]

43. Emilsson L, Wijmenga C, Murray JA, et al. Autoimmune Disease in First-Degree Relatives and Spouses of Individuals With Celiac Disease. Clin Gastroenterol Hepatol. 2015; 13:1271-7. [PubMed: 25645875]

44. Elfstrom P, Montgomery SM, Kampe O, et al. Risk of thyroid disease in individuals with celiac disease. J Clin Endocrinol Metab. 2008; 93:3915-21. [PubMed: 18611971]

45. Murray JA, McLachlan S, Adams PC, et al. Association between celiac disease and iron deficiency in Caucasians, but not non-Caucasians. Clin Gastroenterol Hepatol. 2013; 11:808-14. [PubMed: 23416278]

46. Barton SH, Kelly DG, Murray JA. Nutritional deficiencies in celiac disease. Gastroenterol Clin North Am. 2007; 36:93-108. vi. [PubMed: 17472877]

47. Ludvigsson JF, Rubio-Tapia A, van Dyke CT, et al. Increasing incidence of celiac disease in a North American population. Am J Gastroenterol. 2013; 108:818-24. [PubMed: 23511460]

48. Hallert C, Granno C, Grant C, et al. Quality of life of adult coeliac patients treated for 10 years. Scand J Gastroenterol. 1998; 33:933-8. [PubMed: 9759948]

49. Whitaker JK, West J, Holmes GK, et al. Patient perceptions of the burden of coeliac disease and its treatment in the UK. Aliment Pharmacol Ther. 2009; 29:1131-6. [PubMed: 19245681]

50. Lohi S, Maki M, Montonen J, et al. Malignancies in cases with screening-identified evidence of coeliac disease: a long-term population-based cohort study. Gut. 2009; 58:643-7. [PubMed: 18852259]

51. Katz KD, Rashtak S, Lahr BD, et al. Screening for celiac disease in a North American population: sequential serology and gastrointestinal symptoms. Am J Gastroenterol. 2011; 106:1333-9. [PubMed: 21364545] 

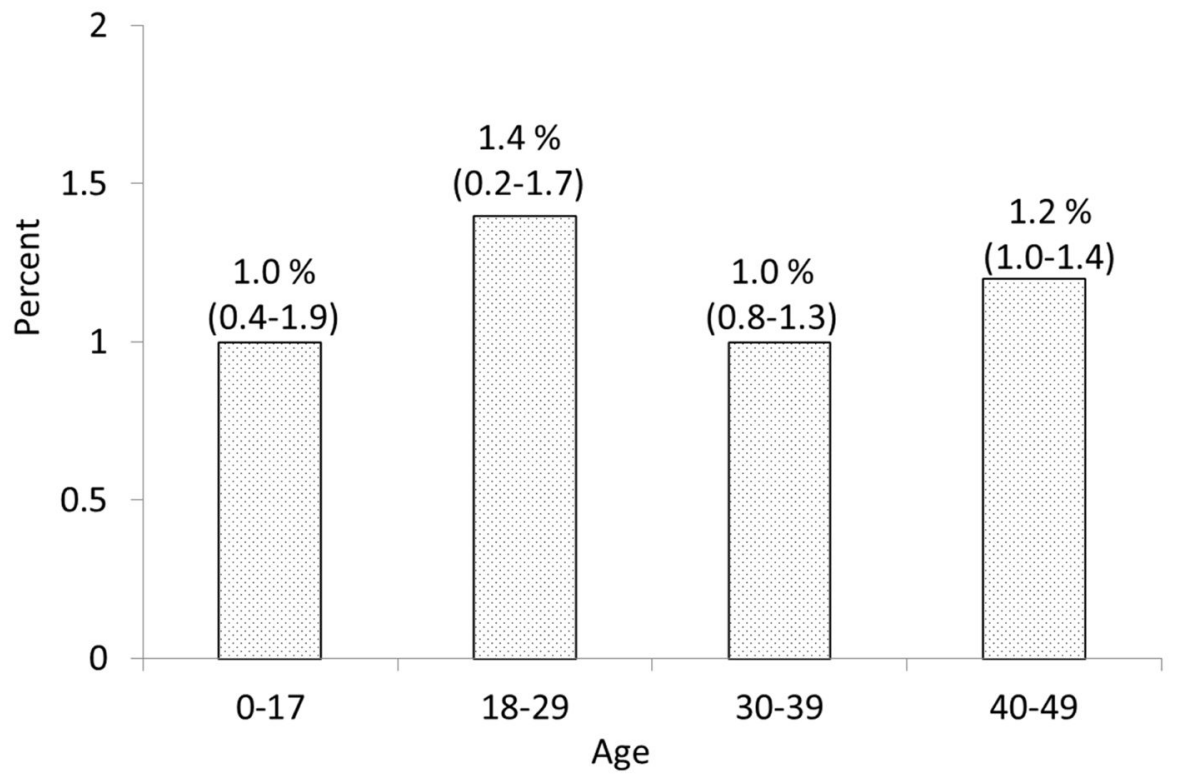

Figure 1.

The prevalence of undiagnosed celiac disease based on tissue transglutaminase IgA (tTGA) according to age categories. Positive was defined by tTGA $\geq 4 \mathrm{U} / \mathrm{mL}$ 


\section{A}
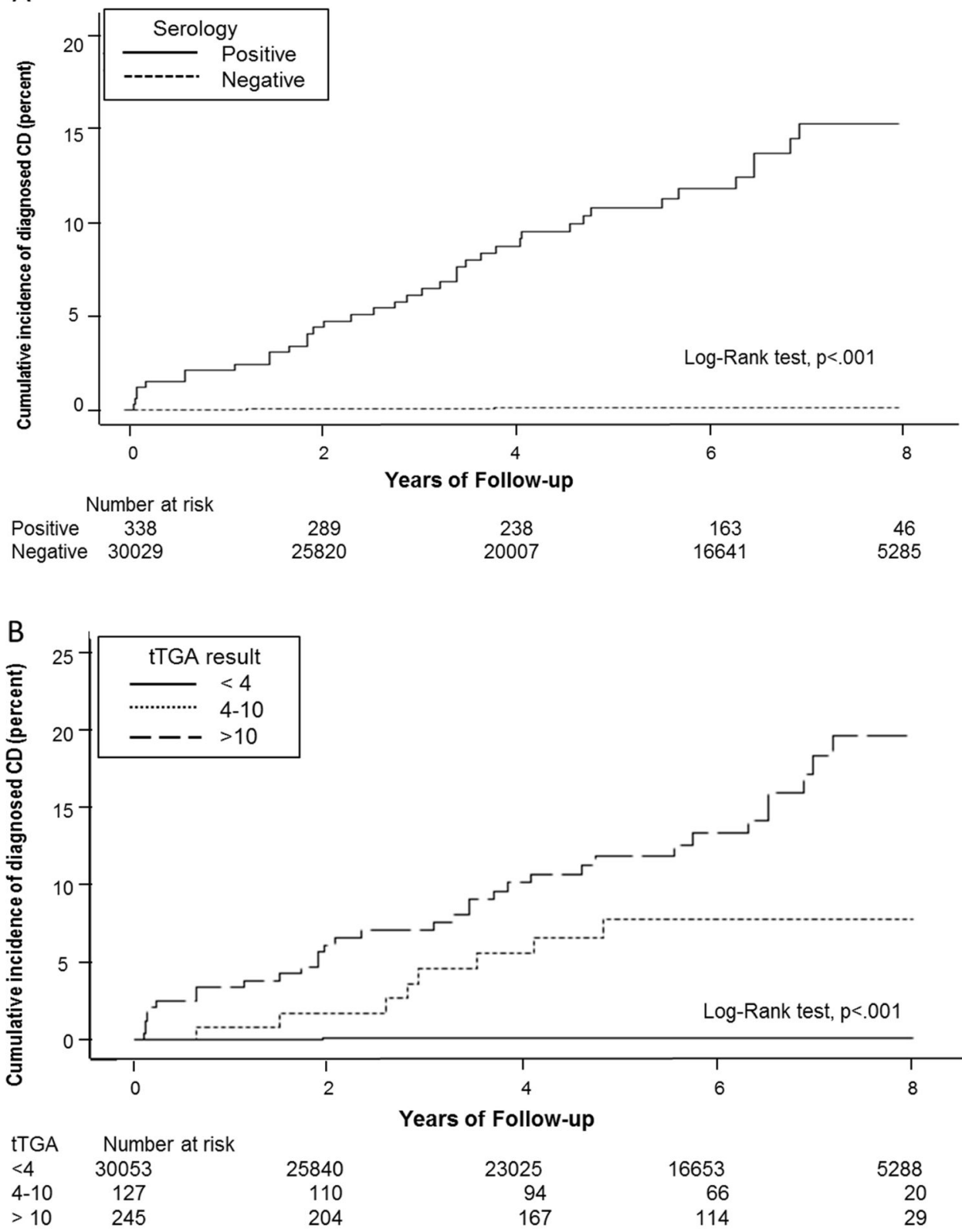

Figure 2.

Cumulative incidence of clinical diagnosis based on celiac disease serology status. A. Individuals are grouped according to serology result after those with equivocal serology were excluded. The cumulative incidence of clinical diagnosis was significantly higher in individuals with undiagnosed celiac disease compared to controls. B. According to categories of tTG titers $(<4,4-10$, or $\geq 10 \mathrm{U} / \mathrm{mL})$, event rates were significantly higher in individuals with strong tTG positive. 


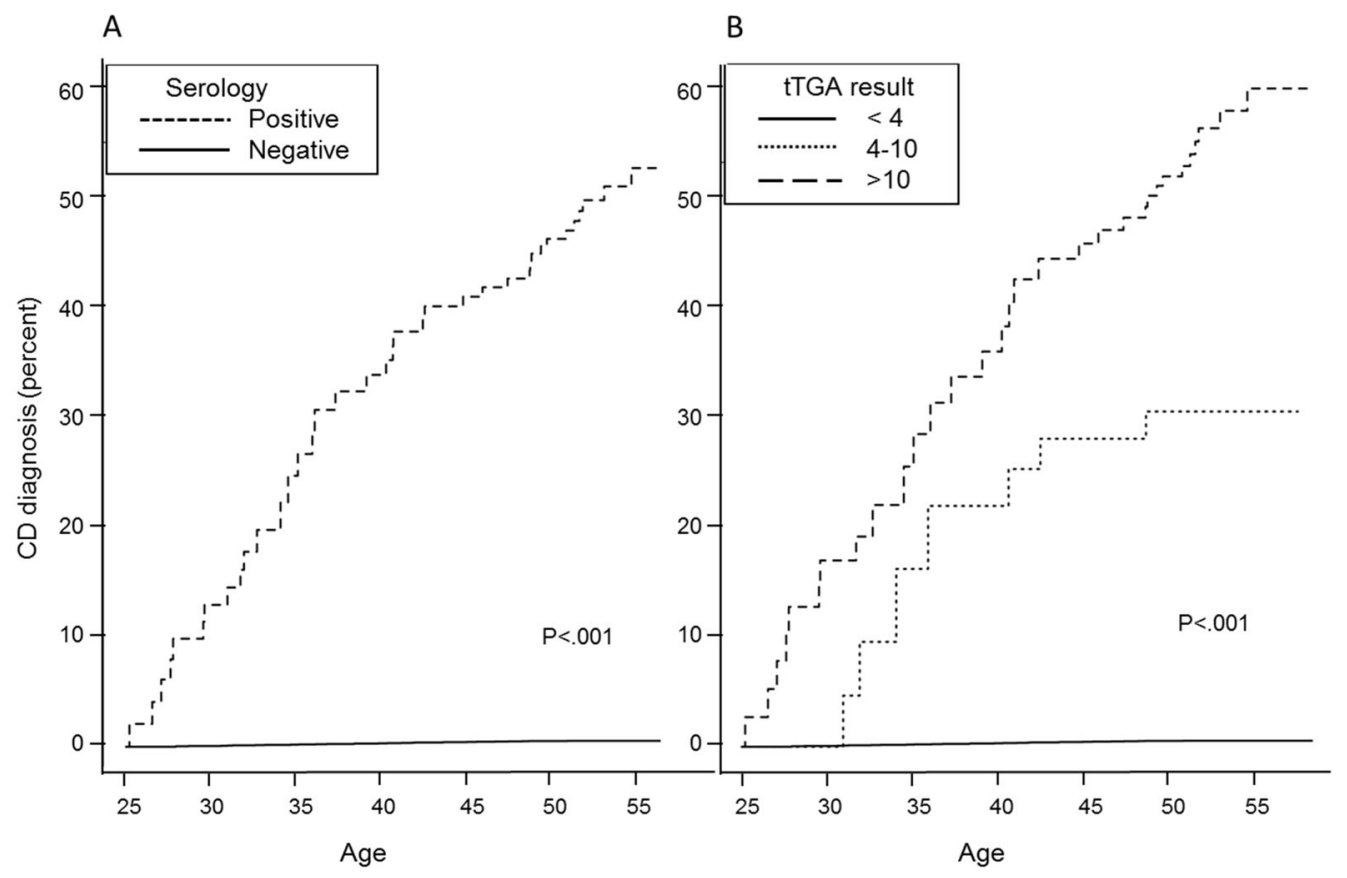

Figure 3.

Cumulative event rate of clinical diagnosis for cohort members according to their age, estimated as a function of their age rather than time after blood draw. A. Individuals are grouped according to serology result after those with equivocal serology were excluded. The cumulative rate of celiac disease diagnosis across age was markedly higher in seropositive persons ( $\mathrm{p}<.001)$, in whom median age at celiac disease diagnosis was 53.1 years. B. All individuals in the cohort are included and grouped according to tTGA $<44-10$, or $\geq 10$ $\mathrm{U} / \mathrm{mL}$, event rates across age were higher for increasing tTGA levels $(\mathrm{p}<.001)$, with median age at celiac disease diagnosis of 49.7 years for individuals with tTGA $\geq 10 \mathrm{U} / \mathrm{mL}$.

tTGA=Tissue transglutaminase immunoglobulin A 


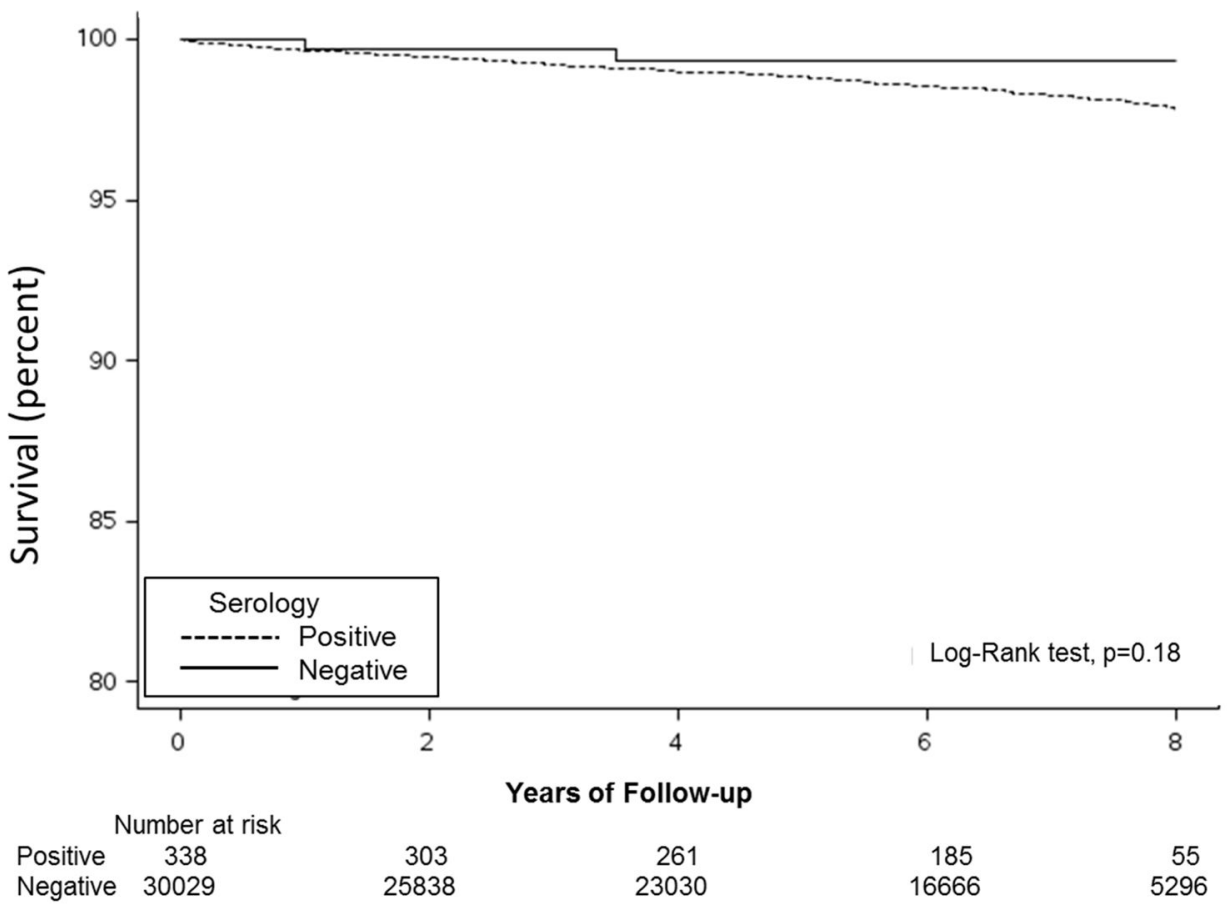

Figure 4.

Kaplan-Meier survival curve for persons with positive and negative serology. 
Table 1

Demographic Characteristics of Participants in the Nested Case Control Cohort ${ }^{a}$

\begin{tabular}{|c|c|c|c|c|}
\hline Characteristic (Total No.) ${ }^{a}$ & Missing, No. (\%) & Serology Negative $(n=562)$ & Serology Positive $(\mathrm{n}=281)$ & $\begin{array}{l}\text { Matched Result } b \text { OR } \\
(95 \% \text { CI })(P \text { Value })\end{array}$ \\
\hline Age at serum draw, $y(n=843)$, & $0(0)$ & $35.1(9.5)$ & $35.1(9.5)$ & NA \\
\hline Female sex $(n=843)$ & $0(0)$ & $358(64)$ & $179(64)$ & NA \\
\hline Race $(\mathrm{n}=755)$ & $88(10)$ & & & Overall $P=.02$ \\
\hline Caucasian & & $453(90 \%)$ & $243(96 \%)$ & 1.0 (reference) \\
\hline African American & & $20(4 \%)$ & $2(1 \%)$ & $0.13(0.03-0.66)$ \\
\hline Asian & & $24(5 \%)$ & $3(1 \%)$ & $0.23(0.07-0.82)$ \\
\hline Other & & $6(1 \%)$ & $4(2 \%)$ & $1.13(0.29-4.36)$ \\
\hline Weight, kg (n=763) & $80(9)$ & $81.1(23.6)$ & 80.7 (19.6) & $0.99(0.92-1.08)(.85)^{\mathcal{C}}$ \\
\hline Height, $\mathrm{cm}(\mathrm{n}=773)$ & $70(8)$ & $169.5(9.8)$ & $169.3(9.6)$ & $0.98(0.79-1.22)(.88)^{\mathcal{C}}$ \\
\hline BMI, $\mathrm{kg} / \mathrm{m}^{2}(\mathrm{n}=737)$ & $106(13)$ & $28.1(7.3)$ & $28.1(6.1)$ & $1.00(0.79-1.27)(.99)^{c}$ \\
\hline BMI categories $(\mathrm{n}=737)^{a}$ & $106(13)$ & & & Overall $P=.09$ \\
\hline$<25$ & & $203(42)$ & $90(36)$ & 1.0 (reference) \\
\hline $25-30$ & & $127(26)$ & $83(33)$ & $1.66(1.10-2.50)$ \\
\hline $30-35$ & & $76(16)$ & $40(16)$ & $1.34(0.82-2.19)$ \\
\hline$>35$ & & $81(17)$ & $37(15)$ & $1.10(0.66-1.82)$ \\
\hline
\end{tabular}

Abbreviations: BMI, body mass index; NA, not applicable; OR, odds ratio; CI, confidence interval.

${ }^{a}$ Categorical variables are presented as number (percentage) of available responses and continuous data as mean $( \pm \mathrm{SD})$.

${ }^{b}$ Each variable was assessed for an association with positive serology using matched analysis (conditional logistic regression analyzed on matched sets, with matching variables included as adjusting covariates in each model).

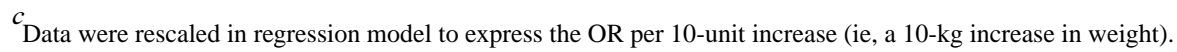


Table 2

Comorbid Conditions and Laboratory Evaluations of Individuals With Undiagnosed Celiac Disease Compared With Serology-Negative Controls

\begin{tabular}{|c|c|c|c|}
\hline & $\underset{(n=562)}{\text { Serology Negative, No. }(\%)}$ & $\underset{(\mathrm{n}=\mathbf{2 8 1})}{\operatorname{Serology}} \underset{\mathrm{Positive,No}}{(\%)}$ & $\begin{array}{c}\text { Matched Result, } b \text { OR }(95 \% \text { CI })(P \\
\text { Value })\end{array}$ \\
\hline \multicolumn{4}{|l|}{ Comorbid conditions $^{a}$} \\
\hline Diabetes mellitus type $1(n=834)$ & $3(1)$ & $5(2)$ & $3.05(0.72-12.86)(.13)$ \\
\hline Glucose intolerance $(\mathrm{n}=820)$ & $14(3)$ & $9(3)$ & $1.40(0.60-3.27)(.44)$ \\
\hline Diabetes mellitus type $2(n=819)$ & $12(2)$ & $10(4)$ & $1.81(0.74-4.43)(.19)$ \\
\hline Hypothyroid (n=834) & $26(5)$ & $25(9)$ & $2.20(1.21-4.01)(<.01)^{c}$ \\
\hline Hyperthyroid $(\mathrm{n}=817)$ & $1(<1)$ & $4(1)$ & $7.68(0.84-70.13)(.07)$ \\
\hline Any autoimmune disorder $(\mathrm{n}=835)$ & $98(18)$ & $67(24)$ & $1.58(1.08,2.30)(.02)^{c}$ \\
\hline Gastroenteritis $(\mathrm{n}=826)$ & $37(7)$ & $17(6)$ & $0.92(0.50-1.66)(.77)$ \\
\hline Neuropathy (n=831) & $6(1)$ & $5(2)$ & $1.79(0.51-6.35)(.36)$ \\
\hline Depression $(\mathrm{n}=828)$ & $128(23)$ & $58(21)$ & $0.91(0.62-1.33)(.62)$ \\
\hline Fibromyalgia $(\mathrm{n}=827)$ & $11(2)$ & $1(<1)$ & $0.15(0.02-1.24)(.08)$ \\
\hline Chronic fatigue $(\mathrm{n}=836)$ & $43(8)$ & $30(11)$ & $1.52(0.93-2.49)(.10)$ \\
\hline Ever had a fracture $(\mathrm{n}=843)$ & $58(10)$ & $27(10)$ & $0.91(0.55-1.49)(.70)$ \\
\hline Ever had osteopenia $(\mathrm{n}=843)$ & $8(1)$ & $2(1)$ & $0.48(0.10-2.29)(.36)$ \\
\hline Ever had osteoporosis $(\mathrm{n}=843)$ & $2(<1)$ & $1(<1)$ & $0.99(0.09-10.95)(>.99)$ \\
\hline \multicolumn{4}{|l|}{ Laboratory findings } \\
\hline Hemoglobin, $\mathrm{g} / \mathrm{dL}^{c}(\mathrm{n}=564)$ & $13.7(1.5)$ & $13.7(1.5)$ & $1.05(0.91-1.21)(.52)$ \\
\hline Cholesterol, mg/dL ${ }^{c}(\mathrm{n}=526)$ & $187.8(36.6)$ & $180.4(40.3)$ & $0.95(0.90-1.00)(.03)^{d}$ \\
\hline Vitamin $B_{12}, n g / L e(n=48)$ & $422.0(287.0-552.0)$ & $423.0(266.0-437.0)$ & $0.54(0.27-1.11)(.10)$ \\
\hline Serum folate, $\mathrm{mcg} / \mathrm{L}^{e}(\mathrm{n}=34)$ & $13.2(10.0-15.7)$ & $11.1(7.5-15.7)$ & $0.63(0.27-1.50)(.30)$ \\
\hline Iron, $\mathrm{mcg} / \mathrm{dL}^{e}(\mathrm{n}=52)$ & $78.5(55.0-106.0)$ & $77.5(34.0-114.0)$ & $0.85(0.47-1.54)(.59)$ \\
\hline Ferritin, $\mathrm{mcg} / \mathrm{L}^{e}(\mathrm{n}=98)$ & $32.0(15.0-74.0)$ & $13.0(5.0-39.0)$ & $0.45(0.24-0.86)(.02)$ \\
\hline Total vitamin $\mathrm{D}, \mathrm{ng} / \mathrm{mL}^{e}(\mathrm{n}=30)$ & $25.5(20.5-34.5)$ & $32.5(20.0-40.0)$ & $1.02(0.48-2.17)(.97)$ \\
\hline Albumin, $\mathrm{g} / \mathrm{dL}^{e}(\mathrm{n}=76)$ & $4.1(3.9-4.5)$ & $4.3(3.9-4.5)$ & $1.18(0.68-2.04)(.56)$ \\
\hline \multicolumn{4}{|c|}{ Abbreviation: OR, odds ratio; $\mathrm{CI}$ confidence interval; $\mathrm{SD}$, standard deviation } \\
\hline \multicolumn{4}{|c|}{${ }^{a}$ Comorbid conditions are presented as count (percentage) of available responses. } \\
\hline \multicolumn{4}{|c|}{$\begin{array}{l}b \text { Each comorbid condition was assessed for an association with positive serology using matched analysis (conditional logistic regression performed } \\
\text { on matched sets, with matching variables included as adjusting covariates in each model). Bold indicates statistical significance. }\end{array}$} \\
\hline \multicolumn{4}{|c|}{$\begin{array}{l}c \text { Laboratory variables are presented as mean (SD) and as unit OR to describe the effect on odds of positive serology from increasing the variable by } \\
1 \text { unit. }\end{array}$} \\
\hline \multicolumn{4}{|c|}{$\begin{array}{l}d \text { Reported OR describes the effect on odds of positive serology to affect cholesterol by } 10 \mathrm{mg} / \mathrm{dL} \text {. } \\
\text {. }\end{array}$} \\
\hline
\end{tabular}

Gastroenterology. Author manuscript; available in PMC 2018 March 01. 


\section{Table 3}

Health Care Utilization over 6 years around serum collection according to celiac disease serology status

\begin{tabular}{lccc}
\hline Variable & Serology Negative $(\mathbf{n = 5 6 2})$ & Serology Positive $(\mathbf{n}=\mathbf{2 8 1})$ & OR $(\mathbf{9 5 \%}$ CI) $[\mathbf{P}$-value $]$ \\
\hline Number of Encounters $(\mathrm{n}=843)$ & $31.6(13.0,43.0)$ & $29.9(15.0,37.0)$ & $0.99(0.84-1.16)[.87]$ \\
Number of Inpatient Encounters $(\mathrm{n}=843)$ & $0.7(0.0,1.0)$ & $0.6(0.0,1.0)$ & $0.92(0.80-1.07)[.30]$ \\
Number of Outpatient Encounters $(\mathrm{n}=843)$ & $30.9(13.0,43.0)$ & $29.2(15.0,36.0)$ & $0.99(0.84-1.16)[.87]$ \\
Number of ER Visits $(\mathrm{n}=843)$ & $1.9(0.0,2.0)$ & $1.5(0.0,2.0)$ & $0.80(0.68-0.94)[<.01]$ \\
\hline
\end{tabular}

Each count variable is reported as mean (IQR), with odds ratio expressed per 1 SD increase in log-transformed values 